\title{
Exceptionally shear-stable and ultra-strong Ir-Ni-Ta high-temperature metallic glasses at micro/nano scales
}

\author{
Yu-Tian Wang ${ }^{1 \dagger}$, Quan-Feng $\mathrm{He}^{3 \dagger}$, Zi-Jian Wang ${ }^{1}$, Ming-Xing $\mathrm{Li}^{1,2}$, Yan-Hui Liu ${ }^{1,2}$, Yong Yang ${ }^{3 *}$, \\ Bao-An Sun ${ }^{1,2^{*}}$ and Wei-Hua Wang ${ }^{1,2}$
}

\begin{abstract}
Ir-Ni-Ta metallic glasses (MGs) exhibit an array of superior high-temperature properties, making them attractive for applications at high temperatures or in harsh environments. However, Ir-Ni-Ta bulk MGs are quite brittle and often fracture catastrophically even before plastic yielding, significantly undercutting their high-strength advantage. Here, we show that the Ir-Ni-Ta MGs are not intrinsically brittle, but rather malleable when the feature size is reduced to micro/nano-scales. All tested Ir-Ni-Ta MG micropillars with a diameter ranging from $\sim 500 \mathrm{~nm}$ to $\sim 5 \mu \mathrm{m}$ display a large plastic strain above $25 \%$ (the maximum up to $35 \%$ ), together with a yield strength up to $7 \mathrm{GPa}$, well exceeding the strength recorded in most metallic materials. The intrinsic shear stability of Ir-Ni-Ta MGs, as characterized by the normalized shear displacement during a shear event, is much larger than those malleable $\mathrm{Zr}$ - and $\mathrm{Cu}$-based MGs. Our results suggest that Ir-Ni-Ta MGs are excellent candidates for micro/nanoscale structural applications used at high-temperature or extreme conditions.
\end{abstract}

Keywords: micro-compressions, micropillars, intrinsic shear stability, metallic glasses

\section{INTRODUCTION}

A combination of high strength and extended deformability is desirable in engineering structural materials for enabling the next generation of light-weight structures and technologies [14]. However, the two features are nearly exclusive, i.e., increasing the strength is often accompanied by the sacrifice of the ductility. There have been enduring research efforts to explore the metallurgical mechanisms to attain a synergy between the high strength and good ductility in crystalline metals and alloys [5-7]. As a new class of disordered materials, metallic glasses exhibit superb high strength (close to the ideal strength in some cases) and large elastic strain [8], yet the strength-ductility trade-off still persists in MGs [9]. Unlike crystalline alloys, the plastic deformation of MGs is highly localized into nanoscale shear bands, which is prone to become runaway with the assistance of strain softening $[10,11]$. As a result, MGs display a propensity for catastrophic and instantaneous brittle failure [12], which has become the Achilles' heel for their structural applications. Over the past decades, significant efforts have improved the deformability of MGs, mostly focusing on uniformly distributing shear bands via introducing secondary phases or structural inhomogeneities into glassy matrix or hindering the propagation of a single shear band [13-18]. In this sense, the stability of shear banding or shear stability of MGs are essential for the enhanced deformability of MGs. A stable shear band can retard the catastrophic propagation, and hence increase the possibility of inducing the formation of multiple shear bands during the deformation of MGs. Yet, how to achieve large intrinsic shear stability in monolithic MGs remains a major challenge.

Recent studies have shown that the sample size can be a design parameter for achieving high deformability of MGs. When the size is reduced to micro/nano-scales, many macroscopically brittle MGs such as Fe-, Co- and Mg-based MGs can sustain large plastic strain $[19,20]$, as revealed by micro-compression tests. The correlations between the reduced size and other mechanical properties, e.g., yield strength and deformation modes, have also been explored in MGs. Currently, full understanding of the size-dependent mechanical properties is still lacking. However, it is accepted that the shear banding process still prevails during the deformation of MGs with the feature size down to $\sim 150 \mathrm{~nm}$ [21], below which the transition from inhomogeneous shear-band mode to homogenous deformation mode occurs. Therefore, it seems that the large plastic strain sustained by small-size samples is the reflection of the intrinsic shear stability of MGs. Micro/nano-sized MGs with limited volumes contain less or no micro-defects (e.g., cavities or microcracks) which may otherwise exist in the macroscopic MGs and lead to their catastrophic failure.

Ir-Ni-Ta MGs exhibit an extraordinarily high glass transition temperature (up to $1100 \mathrm{~K}$ ), a wide supercooled liquid region $(\sim 136 \mathrm{~K})$ as well as high strength at high temperatures $(3.7 \mathrm{GPa}$ at $1000 \mathrm{~K})$ [22]. The array of these properties enables Ir-Ni-Ta MGs to be thermally formed into small-scale components for applications at high-temperatures or in harsh environments. The Ir-Ni-Ta MGs also have a high Young's modulus $E \sim 263 \mathrm{GPa}$ and a hardness of $\sim 15 \mathrm{GPa}$. According to the correlation between elastic modulus and yield strength $\left(\sigma_{\mathrm{y}} \sim E / 50\right)$ reported in bulk MGs [23], the yield strength of Ir-Ni-Ta MGs is estimated to be at least $5 \mathrm{GPa}$ at room temperature. However, like many other high-strength MGs such as Fe-based and Co-based

\footnotetext{
${ }^{1}$ Institute of Physics, Chinese Academy of Sciences, Beijing 100190, China

${ }^{2}$ Songshan Lake Materials Laboratory, Dongguan 523808, China

${ }^{3}$ Department of Mechanical Engineering, City University of Hong Kong, Kowloon Tong, Kowloon, Hong Kong, China

† The authors contributed equally to this work.

* Corresponding authors (emails: sunba@iphy.ac.cn (Sun BA); yonyang@cityu.edu.hk (Yang Y))
} 
MGs, Ir-Ni-Ta MGs in the bulk form are quite brittle: most of them often fracture in the elastic regime before reaching the yield point, significantly undercutting their strength advantage. Here, we show that the Ir-Ni-Ta MGs are not intrinsically brittle, but rather malleable through the micro-compression tests. The intrinsic shear stability of Ir-Ni-Ta MGs, as indexed by the normalized shear displacement during shearing events, is even larger than those malleable $\mathrm{Zr}$ - and Cu-based MGs. The sizeinduced brittle-to-ductile transition of $\mathrm{Ir}-\mathrm{Ni}$-Ta MGs is discussed in terms of the competition between intrinsic shear stability and fracture instability induced by crack-like defects during deformation.

\section{EXPERIMENTAL SECTION}

Ingots of $\operatorname{Ir}_{35} \mathrm{Ni}_{25} \mathrm{Ta}_{40}$ (at.\%, throughout this paper) were prepared by conventional arc melting of pure Ir, Ni and Ta (purity $>99.95$ at.\%) in a Ti-gettered high-purity Ar atmosphere. The ingots were re-melted at least four times to ensure chemical homogeneity. Then the ingots were cast into 2-mm-diameter rods by copper mold suction casting. The fully amorphous state was examined by an X-ray diffractometer (XRD, Bruker D8A A $25 \mathrm{X}$ ) with $\mathrm{Cu} \mathrm{Ka}$ radiation and a transmission electron microscope (TEM, FEI Talos F200X). Thermal properties were tested by high-temperature differential scanning calorimetry (Netzsch, DSC 404F3) from 303 to $1373 \mathrm{~K}$ at a heating rate of $20 \mathrm{~K} \mathrm{~min}^{-1}$.

The 2-mm-diameter $\operatorname{Ir}_{35} \mathrm{Ni}_{25} \mathrm{Ta}_{40}$ amorphous rod was cut into several cylindrical specimens with a length-diameter ratio of 2:1 (length: $4 \mathrm{~mm}$, diameter: $2 \mathrm{~mm}$ ). Then, the mechanical properties of the millimeter-scale cylindrical specimens were tested under uniaxial compression using a universal mechanical testing system (Instron 3384) at a strain rate of $2 \times 10^{-4} \mathrm{~s}^{-1}$. The rest of cylindrical specimens prepared for mechanical test was polished
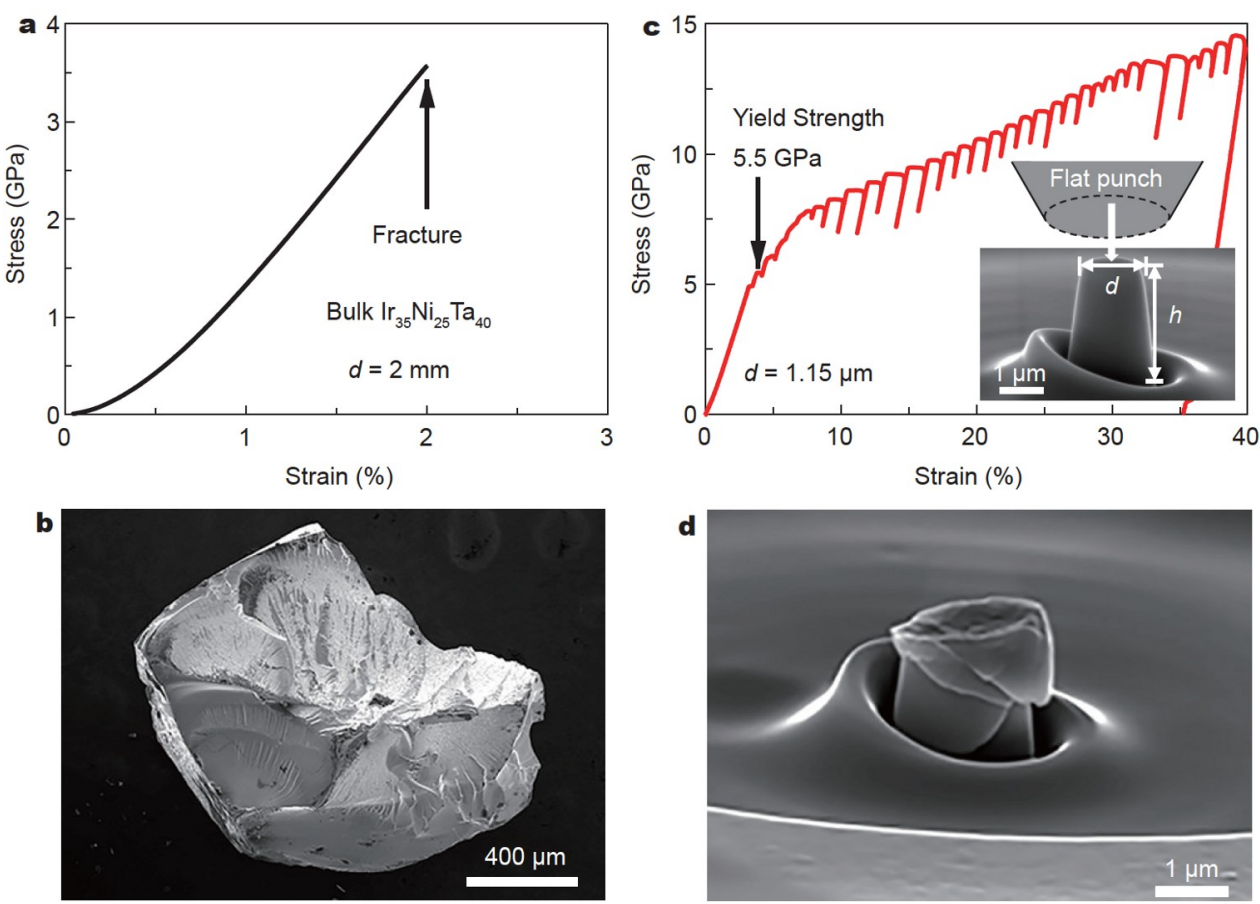

on one side to a mirror finish so as to reduce the effect of substrate roughness on the micro-compression tests of micropillars. The micropillars with diameters from $\sim 500 \mathrm{~nm}$ to $\sim 5 \mu \mathrm{m}$ were fabricated by focused ion beam (FIB) on the polished surface of the disk. Subsequently, ex-situ and in-situ microcompression tests were carried out at a constant strain rate of $8 \times 10^{-3} \mathrm{~s}^{-1}$ under the displacement-controlled mode on the Hysitron nanoindentation systems (Bruker TI 950 and PI 88). Post-mortem scanning electron microscopy (SEM) images were taken by a scanning electron microscope (Thermo Scientific, Quattro S).

\section{RESULTS AND DISCUSSION}

$\mathrm{Ir}_{35} \mathrm{Ni}_{25} \mathrm{Ta}_{40}$ (at.\%) alloy exhibits a good glass-forming ability (GFA) and can be cast into fully glassy rods with a diameter of $2 \mathrm{~mm}$. For the fabrication of small-scale Ir-Ni-Ta MG micropillars, we first prepared the $\operatorname{Ir}_{35} \mathrm{Ni}_{25} \mathrm{Ta}_{40}$ glassy rods with a diameter of $2 \mathrm{~mm}$ through the suction casting method. The structural and thermal characterizations of the Ir-Ni-Ta bulk MGs are shown in Supplementary information. The amorphous nature of the Ir-Ni-Ta rods was verified by the diffuse halo in both XRD patterns and selected area electron diffraction (SAED) patterns, as well as the homogenous and contrastless features in high-resolution TEM image (Figs S1 and S2). The thermal flow curve (Fig. S3) shows an obvious endothermic glass transition event followed by an exothermic crystallization peak, with the glass transition temperature $T_{\mathrm{g}}=1158 \mathrm{~K}$ and the onset crystallization temperature $T_{\mathrm{x}}=1256 \mathrm{~K}$, respectively (Fig. S3). The supercooled liquid region $\left(\Delta T=T_{\mathrm{x}}-T_{\mathrm{g}}\right)$ is $98 \mathrm{~K}$, which is consistent with the previous report [22].

For comparison, we first performed the compression tests on the bulk Ir-Ni-Ta MG. A typical stress-strain curve for $\operatorname{Ir}_{35} \mathrm{Ni}_{25}$ $\mathrm{Ta}_{40}$ bulk MG is shown in Fig. 1a. As can be seen, the bulk

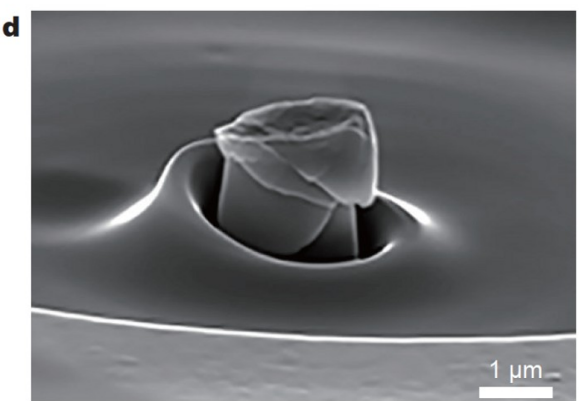

Figure 1 Typical stress-strain curves of $\operatorname{Ir}_{35} \mathrm{Ni}_{25} \mathrm{Ta}_{40} \mathrm{MG}$. (a) Stress-strain curve of $\operatorname{Ir}_{35} \mathrm{Ni}_{25} \mathrm{Ta}_{40}$ rod with a diameter of 2 mm under uniaxial compression. The black arrow indicates the sample fracture with almost no plastic deformation. (b) Engineering stress-strain curve of a $1.15-\mu \mathrm{m}-\mathrm{diameter}_{\mathrm{Ir}} \mathrm{r}_{35} \mathrm{Ni}_{25} \mathrm{Ta}_{40} \mathrm{Pillar}$ under in-situ micro-compression. Inset: schematic diagram of the micro-compression configuration. (c) SEM image of a fracture fragment of the 2-mmdiameter rod. (d) SEM image of the 1.15- $\mu$ m-diameter pillar after in-situ micro-compression. 
sample suddenly fractured in the elastic stage before the stress reached the yield strength with almost no plastic strain. The samples were shattered into small pieces after fracture (see Fig. 1b), indicating a brittle and fragmentation fracture mode. The fracture morphology of Ir-Ni-Ta MG is similar to that of some brittle MGs such as Fe-, Mg- and Co-based MGs [24,25]. This fragmentation fracture has been attributed to microcrackinduced fracture instability where numerous fracture sites nucleate into microcracks simultaneously and propagate rapidly, resulting in local cleavage fracture [25].

In contrast, the deformation of the $\operatorname{Ir}_{35} \mathrm{Ni}_{25} \mathrm{Ta}_{40} \mathrm{MG}$ at micro/ nano-scales is totally different from that of its bulk form. We performed micro-compression tests of the $\operatorname{Ir}_{35} \mathrm{Ni}_{25} \mathrm{Ta}_{40}$ MG micropillars in a nanoindentation equipment using a flat punch. Fig. 1c displays a typical stress-strain curve for the $\operatorname{Ir}_{35} \mathrm{Ni}_{25} \mathrm{Ta}_{40}$ MG pillar with a diameter of $1.15 \mu \mathrm{m}$. It can be seen that the micropillar exhibits a significant plastic regime with a plasticity over $35 \%$ after the elastic deformation stage, in sharp contrast to the brittle fracture of the Ir-Ni-Ta bulk MG (Fig. 1a). There is obvious serrated flow behavior in the plastic flow regime, indicating that the micropillar is still deformed via the intermittent shear banding process (Fig. 1c). This is also verified by the morphology of the deformed sample, where one single shear band and some secondary shear bands are observed (Fig. 1d). The micropillar also has a high yield strength around $5.5 \mathrm{GPa}$, after which the plastic flow stress continuously rises, reaching a maximum strength over $15 \mathrm{GPa}$. Note that the strength of $\mathrm{Ir}_{35} \mathrm{Ni}_{25} \mathrm{Ta}_{40}$ MG micropillar is almost comparable to that of the $\mathrm{Co}_{55} \mathrm{Ta}_{10} \mathrm{~B}_{35}$ MG which is the strongest metallic materials ever reported [26]. The remarkable "work hardening" behavior observed here cannot be attributed to the intrinsic strain hard- ening of Ir-Ni-Ta MGs, since the shear-band-mediated deformation is always related to the strain softening of MGs. Rather, we would like to attribute this behavior to the increasing loading area owing to the tap-like sample shape and the interactions among multiple shear bands during the deformation. Nevertheless, the combination of the high strength and large plasticity of the Ir-Ni-Ta microscale MGs is very unusual and out of the trade-off between strength and plasticity for most metallic materials.

To further study the size effect on the mechanical properties of Ir-Ni-Ta MGs, micro-compression tests on pillars with different diameters ranging from $\sim 500 \mathrm{~nm}$ to $\sim 5 \mu \mathrm{m}$ were carried out. Since the load to yield the pillars with large diameters $(>2 \mu \mathrm{m})$ exceeds $10 \mathrm{mN}$, the pillars with a diameter smaller than $2 \mu \mathrm{m}$ and larger than $2 \mu \mathrm{m}$ were compressed in the low load mode (the load limit $\sim 10 \mathrm{mN}$ ) and the high load mode (the load limit $\sim 20 \mathrm{~N}$ ) of the nanoindentation, respectively. Typical deformation curves for these micropillars are shown in Fig. 2a, b. One can see that all micropillars exhibit an obvious plastic flow regime with a plastic strain above $25 \%$, and a maximum up to $35 \%$. After deformation, obvious shear band behavior for these micropillars and no splitting fracture occur even for the pillars with $\sim 5 \mu \mathrm{m}$ diameter. All these features indicate the good malleability of Ir-Ni-Ta MGs. It is worth noting that the pillars with the diameter smaller than $2 \mu \mathrm{m}$ show discrete and large stress serrations in the deformation curves (Fig. 2a), while the pillars with the diameter larger than $2 \mu \mathrm{m}$ display relatively smooth stress-strain curves (Fig. 2b). The different serrated flow behavior can be attributed to the different frame stiffness for the low load mode and high load mode as well as the different sample stiffness depending on the pillar size. Based on the analysis on
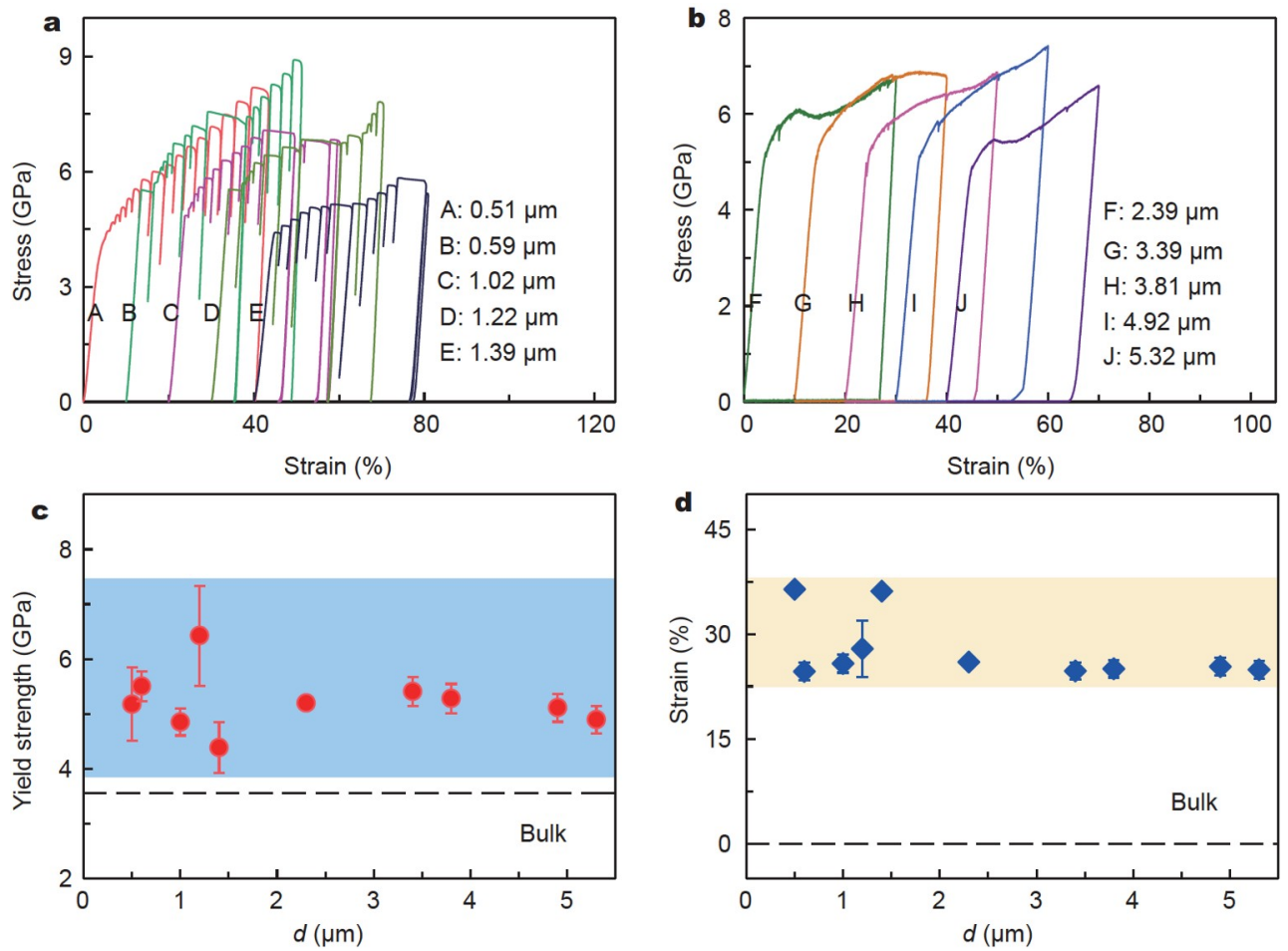

Figure 2 Mechanical properties of $\mathrm{Ir}_{35} \mathrm{Ni}_{25} \mathrm{Ta}_{40} \mathrm{MG}$ micropillars. Engineering stress-strain curves of micropillars with different diameters measured at a constant strain rate of $8 \times 10^{-3} \mathrm{~s}^{-1}$. (a): $0.51,0.59,1.02,1.22$ and $1.39 \mu \mathrm{m}$. (b): $2.39,3.39,3.81,4.92$ and $5.32 \mu \mathrm{m}$. Dependence of (c) the yield strength and (d) the plastic strain extracted from engineering stress-strain curves on the diameter of micropillars. The dash lines in (c, d) denote the strength and plastic strain of the bulk sample. 
the stick-slip shear-band dynamics, the transition from serrated flow to smooth flow is mainly determined by the stiffness constant of machine-sample system, $k$, which is a function of sample size and the stiffness ratio of sample to machine [27]. As the value of $k$ approaching the critical stiffness $k_{\mathrm{cr}}$, the serrated flow will be suppressed and transform into non-serrated or smooth flow.

The yield strength $\sigma_{\mathrm{y}}$ and the final plastic strain $\varepsilon_{\mathrm{y}}$ for all $\mathrm{Ir}_{35} \mathrm{Ni}_{25} \mathrm{Ta}_{40}$ MG micropillars were extracted from the stressstrain curves (Table S1). Fig. 2c, d show the variations of $\sigma_{\mathrm{y}}$ and $\varepsilon_{\mathrm{y}}$ with the pillar diameter, respectively. Although the data of $\sigma_{\mathrm{y}}$ is significantly scattered in a range of $4-7 \mathrm{GPa}$, they show no obvious size dependence. All values of $\sigma_{\mathrm{y}}$ are well above the measured strength of the bulk sample. The size effects on the yield strength of various MGs such as Zr-, Pd-, Al-, Cu-based MGs at micro/nano-scales have been studied extensively [2832]. According to these experimental studies, the strength of some MGs is size-dependent [28-31], while others are not [32]. Whether the strength is size-dependent remains a debating issue. Recently, Li et al. [33] proposed a micromechanical model by taking into account the stochasticity for shear band initiation in micro-compressions. The model shows that a size-controlled stochastic transition from size-dependent to the size-independent yield strength in the MG micropillars is related to an intrinsic length scale which varies with chemical composition. The intrinsic length scale is the critical length at which the shearband embryo develops into a mature shear band and for most MGs this length lies in the range of $0.2-2 \mu \mathrm{m}$. The size-independent yield strength observed here indicates that the intrinsic length scale controlling the stochastic transition for $\mathrm{Ir}-\mathrm{Ni}-\mathrm{Ta}$
MGs is at least $5 \mu \mathrm{m}$ (Fig. 2c), indicating an unusually large length scale for a shear-band embryo developing into a mature shear band for Ir-Ni-Ta MGs. The plasticity values of Ir-Ni-Ta MG micropillars are also significantly scattered in the range of $25 \%-35 \%$, and show no obvious size dependence as well, similar to that of $\sigma_{\mathrm{y}}$. The strong scattering of $\varepsilon_{\mathrm{y}}$ may be also related to the stochastic shear-band initiation sites during micro-compressions, reflecting the intrinsic structural heterogeneities of Ir-NiTa MGs.

To further understand the large plasticity of Ir-Ni-Ta MG micropillars, we analyzed the serrated flow observed in their stress-strain curves. A $0.51-\mu \mathrm{m}$-diameter Ir-Ni-Ta pillar shows remarkable serrated flow behavior under micro-compression and multiple shear bands are observed on it after the microcompression test (Fig. 3a). According to previously experimental and theoretical studies, the serrated flow stress in the uniaxial compressions of MGs is mainly related to the intermittent or stick-slip shear-band sliding along a shear plane [34]. Therefore, the sliding distance of a shear band during a serrated event can serve as a reflection of intrinsic shear stability of the MGs. The longer the shear band can slide during the shear event, the higher is the shear stability of the MGs against the runaway failure and the larger is the plasticity. From the stick-slip model of shear banding, the sliding distance of shear band $\Delta s$ in a single serration is proportional to the stress drop $\Delta \sigma, \Delta \sigma=k \Delta s$ [35]. The coefficient $k$ can be approximately calculated as $k=E /(H+$ $5 d)$ for micro-compressions [19], where $E$ is the Young's modulus, $H$ is the height of micropillars, and $d$ is the diameter of micropillars.

The magnitude of stress drop can be directly read from the
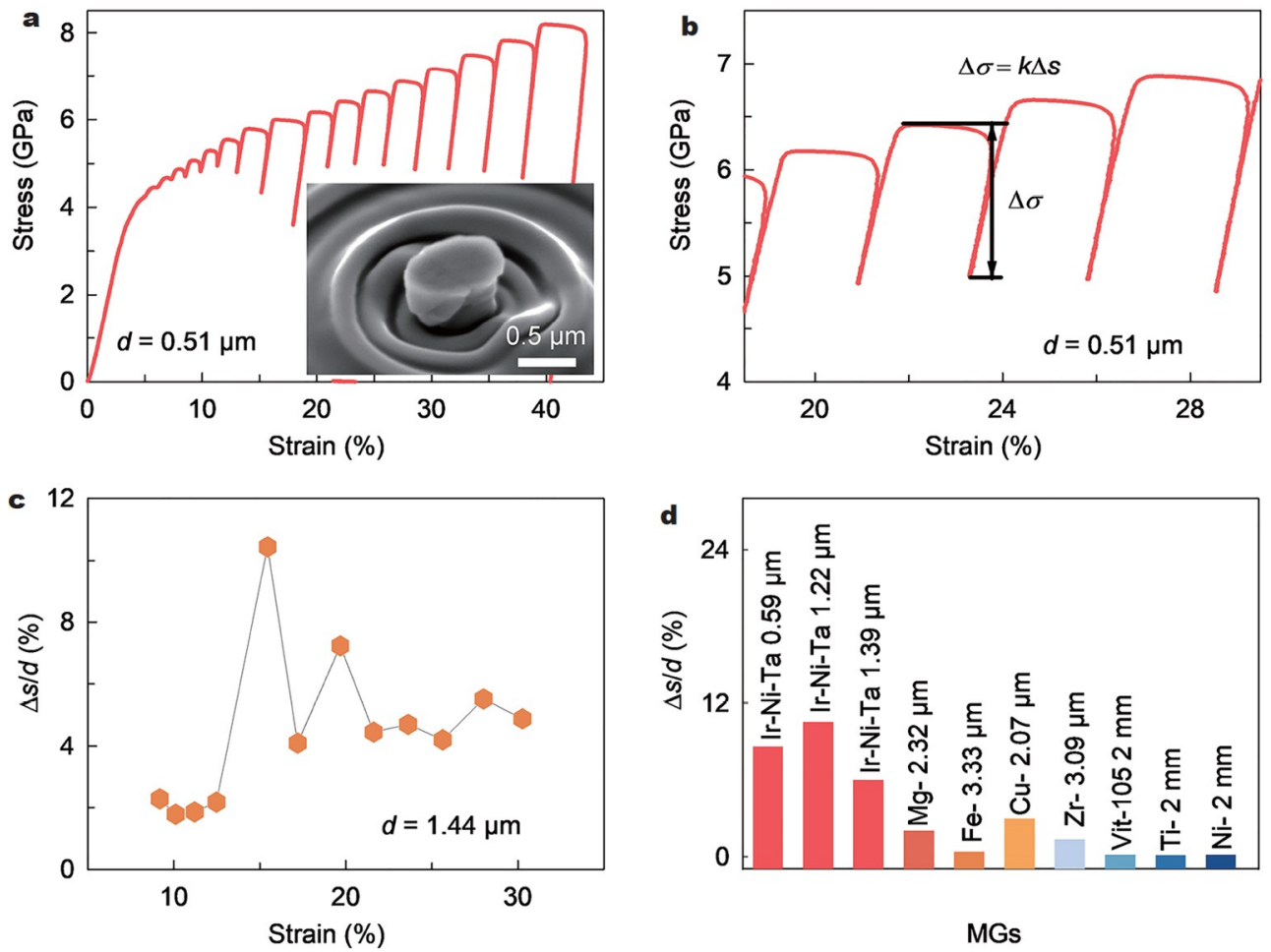

Figure 3 Normalized sliding distance of shear bands for different MGs. (a) Ex-situ micro-compression engineering stress-strain curve of a 0.51- $\mu$ m-diameter pillar. Inset: SEM image of the 0.51- $\mu$ m-diameter pillar after micro-compression test. (b) Enlarged portion of engineering stress-strain curve of the 0.51- $\mu$ mdiameter pillar showing the stress drop $\Delta \sigma$ used to calculate the $\Delta s$. (c) Normalized shear-band sliding distance $\Delta s / d$ versus strain of a 1.44 - $\mu$ m-diameter micropillar. (d) Comparison of the normalized shear-band sliding distance $\Delta s / d$ of different MGs [19,36,37]. 
stress-strain curve (Fig. 3b), and the coefficient $k$ for microcompression tests can be calculated via $k=E /(H+5 d)$, where $E$ is the Young's modulus of the material and is measured to be $204 \mathrm{GPa}$ for $\operatorname{Ir}_{35} \mathrm{Ni}_{25} \mathrm{Ta}_{40}$ MG (Fig. S4), the $\Delta s$ of each serration in the stress-strain curve of $\operatorname{Ir}_{35} \mathrm{Ni}_{25} \mathrm{Ta}_{40}$ MG micropillars is calculated (Fig. 3b), and then is normalized by the diameter of MG sample $d$ in order to compare with other MG samples with different sizes. Fig. $3 c$ shows the diameter-normalized shear band sliding distance $\Delta s / d$ at different strains for a 1.44-umdiamater Ir-Ni-Ta MG pillar. It can be seen that the value of $\Delta s / d$ spans from about $2 \%$ to above $10 \%$, and there are no clear correlations between $\Delta s / d$ and strain (Fig. 3c). Thus, the mean value of $\Delta s / d$ is calculated to serve as a measure of the shear stability of the sample. The mean value of $\Delta s / d$ for each MG sample can be obtained by averaging all serrations in the stressstrain curve. The value of mean $\Delta s / d$ for MG samples of different alloy compositions and diameters (including the bulk MGs) is calculated and shown in Fig. 3d. For the uniaxial compression of bulk MGs, $k=E / L(1+S)$ [27], where $L$ is the sample height, and $S$ is the ratio of sample stiffness to the machine stiffness. The values of the mean $\Delta s / d$ of Ir-Ni-Ta MG micropillars are much larger than that of other MGs systems (Fig. 3d). The maximum value of the mean $\Delta s / d$ for Ir-Ni-Ta MGs (the 1.22- $\mu$ m-diameter pillar) reaches $10.56 \%$, which is the largest among all MG micropillars (Ir-, Mg-, Fe-, $\mathrm{Cu}-$ and Zr-based MGs) [19]. Besides, the mean $\Delta s / d$ of Ir-Ni-Ta MGs micropillars is even two orders of magnitude larger than that of $\mathrm{Zr}-$, Ti- and Ni-based bulk MGs $[27,36,37]$, indicating the extraordinary intrinsic shear stability of the Ir-Ni-Ta MGs. The large $\Delta s / d$ suggests that the dominant shear band is stable during sliding, thereby increasing the possibility of forming multiple shear bands and ultimately resulting in the large plasticity of $\mathrm{Ir}-\mathrm{Ni}$-Ta MG micropillars.

In order to directly observe the deformation process of $\mathrm{Ir}-\mathrm{Ni}$ Ta micropillars, in-situ micro-compression tests were conducted. A video of the deformation process of a typical $\mathrm{Ir}_{35} \mathrm{Ni}_{25} \mathrm{Ta}_{40}$ MG pillar (with a diameter of $1.44 \mu \mathrm{m}$ ) is provided in Video S1, and the stress-strain curve of the 1.44- $\mu$ m-diameter pillar was obtained simultaneously (Fig. 4a). In order to clarify the shear-band evolution during deformation, the SEM images in Fig. 4b-e were extracted from the video corresponding to different deformation positions (Serrations 1-4) on the strainstress curve in Fig. 4a. At the initial stage of plastic deformation (Serration 1), only one single shear band is observed (Fig. 4b), and the small serrations observed in the stress curve may correspond to the stick-slip motion of the single shear band. With the evolution of deformation, some secondary shear bands appear (Fig. 4c). The interplay between these secondary shear bands and the dominant shear band can result in large shear avalanches and even the large serrations (e.g., Serration 2). The number of shear bands continues to increase with the deformation, and significant shear offset (Fig. 4d) along the primary shear band can be seen on the sample surface at the position of Serration 3 ( $\sim 25 \%$ plastic strain). Finally, some very large stress serrations can be seen around Serration 4 close to the final failure and some cracks have formed along the large shear offset of the primary shear band (Fig. 4e). The large sliding displacement of the dominant shear band as seen in the video indicates the extraordinary intrinsic shear stability of Ir-Ni-Ta MGs at microscales.

From the above results, we can see that the fail mode for Ir$\mathrm{Ni}$-Ta MGs is splitting or fragmentation fracture when the sample is in the bulk form, and it gradually becomes shear fracture when the size is reduced down to the microscales. According to the fragmentation fracture model proposed by Zhang et al. [38], the fragmentation degree of the fracture for a MG sample can be reflected by a parameter $F_{n}$, which is defined as the ratio of new created surface area $A_{n}$ after fracture to the original surface area $A_{0}$ of the sample. For a cylinder sample with a volume $V_{0}$ and a height $H, F_{n}$ correlates with material properties by the relation:

$F_{n}=\frac{\eta \sigma_{\mathrm{F}}^{2} V_{0}}{2 E \gamma A_{0}}=\frac{\eta \sigma_{\mathrm{F}}^{2} H}{20 E \gamma}$

where $\eta$ is the efficiency of the elastic energy transferring to surface energy, $\gamma$ is the surface energy, and $E$ and $\sigma_{\mathrm{F}}$ are the Young's modulus and fracture strength of the sample, respectively. The MG sample with a large $F_{n}$ is prone to fracture into more pieces. The shear fracture can be viewed as a special fragmentation model with $n=2$, and in this case, $F_{n}$ is a rather small constant ( $\sim 0.28)$. From Equation (1), one can see that $F_{n}$ is proportional to the sample height. For a bulk Ir-Ni-Ta MG sample, the $F_{n}$ should be very high considering their high fracture strength $\sigma_{\mathrm{F}}$ comparable to those of Co-based MGs [26]. Therefore, the Ir-Ni-Ta MG bulk samples are prone to fracture into many pieces through rapid propagation of many local cracks. While at microscales, the height of Ir-Ni-Ta MG micropillars is reduced almost three orders of magnitude, resulting in a small $F_{n}$. In this case, fragmentation fracture is largely suppressed, and consequently, it is possible for the nucleation and propagation of shear bands, which dominate the
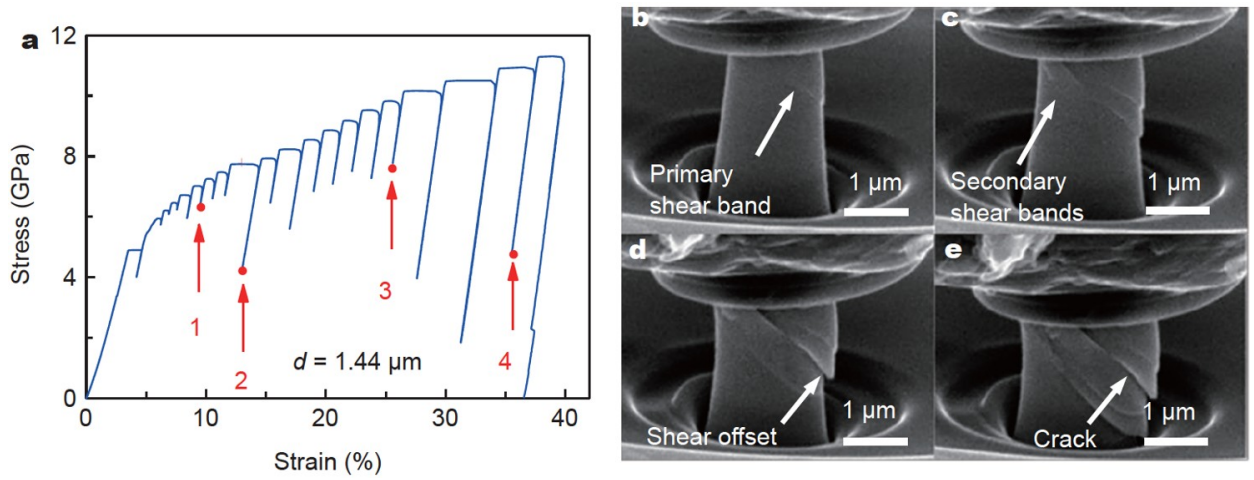

Figure 4 In-situ micro-compression test of a 1.44- $\mu \mathrm{m}$-diameter pillar. (a) In-situ micro-compression engineering stress-strain curve of the 1.44- $\mu$ m-diameter pillar. (b-e) In-situ SEM images of the pillar at the four different stages marked in (a) during the compression test. 
subsequent deformation and fracture process. So the sizeinduced brittle-to-ductile transition of $\mathrm{Ir}-\mathrm{Ni}$-Ta MGs can be interpreted as a competition between the crack-like defectsinduced fracture instability and intrinsic shear-banding stability during deformation.

\section{CONCLUSIONS}

To conclude, Ir-Ni-Ta microscale MGs exhibit the extraordinary shear stability characterized by a large value of $\Delta s / d$ and a giant plastic strain $25 \%-35 \%$, together with an extremely high yield strength up to $7 \mathrm{GPa}$. The improved deformability of Ir-Ni-Ta MGs is explained by the competition between the crack-induced fracture instability and the intrinsic shear stability with the size reduction. Combining the high glass transition temperature and good thermoplastic-forming ability in the supercooled liquid region and superior oxidation and corrosion resistance, the shear-stable microscale Ir-Ni-Ta MGs are promising for the micro/nano-scales structural parts not only at low and ambient temperatures, such as micro-gears, but also at high-temperature or in harsh conditions, such as high-precision moulds for thermal-forming microlens arrays.

\section{Received 30 June 2021; accepted 26 July 2021; published online 6 September 2021}

1 Shi S, Li Y, Ngo-Dinh BN, et al. Scaling behavior of stiffness and strength of hierarchical network nanomaterials. Science, 2021, 371: 1026-1033

2 Wang Y, Huang X, Zhang X. Ultrarobust, tough and highly stretchable self-healing materials based on cartilage-inspired noncovalent assembly nanostructure. Nat Commun, 2021, 12: 1291

$3 \mathrm{Hu} \mathrm{K}$, Lin $\mathrm{K}, \mathrm{Gu} \mathrm{D}$, et al. Mechanical properties and deformation behavior under compressive loading of selective laser melting processed bio-inspired sandwich structures. Mater Sci Eng-A, 2019, 762: 138089

4 Zhou F, Sun W, Zhang C, et al. 3D freestanding DNA nanostructure hybrid as a low-density high-strength material. ACS Nano, 2020, 14: 6582-6588

5 Wu G, Liu C, Sun L, et al. Hierarchical nanostructured aluminum alloy with ultrahigh strength and large plasticity. Nat Commun, 2019, 10: 5099

6 Wu G, Chan KC, Zhu L, et al. Dual-phase nanostructuring as a route to high-strength magnesium alloys. Nature, 2017, 545: 80-83

7 Yang T, Zhao YL, Li WP, et al. Ultrahigh-strength and ductile superlattice alloys with nanoscale disordered interfaces. Science, 2020, 369: 427-432

8 Tian L, Cheng YQ, Shan ZW, et al. Approaching the ideal elastic limit of metallic glasses. Nat Commun, 2012, 3: 609

9 Egami T, Iwashita T, Dmowski W. Mechanical properties of metallic glasses. Metals, 2013, 3: 77-113

10 Greer AL, Cheng YQ, Ma E. Shear bands in metallic glasses. Mater Sci Eng-R-Rep, 2013, 74: 71-132

11 Dong J, Huan Y, Huang B, et al. Unusually thick shear-softening surface of micrometer-size metallic glasses. Innovation, 2021, 2: 100106

12 Shen LQ, Yu JH, Tang XC, et al. Observation of cavitation governing fracture in glasses. Sci Adv, 2021, 7: eabf7293

13 Zhang L, Jiang F, Zhang D, et al. In-situ precipitated nanocrystal beneficial to enhanced plasticity of $\mathrm{Cu}-\mathrm{Zr}$ based bulk metallic glasses. Adv Eng Mater, 2008, 10: 943-950

14 Wu FF, Chan KC, Jiang SS, et al. Bulk metallic glass composite with good tensile ductility, high strength and large elastic strain limit. Sci Rep, 2015, 4: 5302

15 Fan J, Qiao JW, Wang ZH, et al. Twinning-induced plasticity (TWIP) and work hardening in Ti-based metallic glass matrix composites. Sci Rep, 2017, 7: 1877

16 Ketov SV, Sun YH, Nachum S, et al. Rejuvenation of metallic glasses by non-affine thermal strain. Nature, 2015, 524: 200-203

17 Jang D, Greer JR. Transition from a strong-yet-brittle to a strongerand-ductile state by size reduction of metallic glasses. Nat Mater, 2010, 9: $215-219$

18 Guo H, Yan PF, Wang YB, et al. Tensile ductility and necking of metallic glass. Nat Mater, 2007, 6: 735-739

19 Ke HB, Sun BA, Liu CT, et al. Effect of size and base-element on the jerky flow dynamics in metallic glass. Acta Mater, 2014, 63: 180-190

$20 \mathrm{Qu}$ R, Tönnies D, Tian L, et al. Size-dependent failure of the strongest bulk metallic glass. Acta Mater, 2019, 178: 249-262

$21 \mathrm{Wu}$ XL, Guo YZ, Wei Q, et al. Prevalence of shear banding in compression of $\mathrm{Zr}_{41} \mathrm{Ti}_{14} \mathrm{Cu}_{12.5} \mathrm{Ni}_{10} \mathrm{Be}_{22.5}$ pillars as small as $150 \mathrm{~nm}$ in diameter. Acta Mater, 2009, 57: 3562-3571

22 Li MX, Zhao SF, Lu Z, et al. High-temperature bulk metallic glasses developed by combinatorial methods. Nature, 2019, 569: 99-103

23 Wang WH. Correlations between elastic moduli and properties in bulk metallic glasses. J Appl Phys, 2006, 99: 093506

24 Xi XK, Zhao DQ, Pan MX, et al. Fracture of brittle metallic glasses: Brittleness or plasticity. Phys Rev Lett, 2005, 94: 125510

25 Zhao JX, Qu RT, Wu FF, et al. Fracture mechanism of some brittle metallic glasses. J Appl Phys, 2009, 105: 103519

26 Wang J, Li R, Hua N, et al. Co-based ternary bulk metallic glasses with ultrahigh strength and plasticity. J Mater Res, 2011, 26: 2072-2079

27 Sun BA, Pauly S, Hu J, et al. Origin of intermittent plastic flow and instability of shear band sliding in bulk metallic glasses. Phys Rev Lett, 2013, 110: 225501

28 Lai YH, Lee CJ, Cheng YT, et al. Bulk and microscale compressive behavior of a Zr-based metallic glass. Scripta Mater, 2008, 58: 890-893

29 Volkert CA, Donohue A, Spaepen F. Effect of sample size on deformation in amorphous metals. J Appl Phys, 2008, 103: 083539

30 Wang CC, Ding J, Cheng YQ, et al. Sample size matters for $\mathrm{Al}_{88} \mathrm{Fe}_{7} \mathrm{Gd}_{5}$ metallic glass: Smaller is stronger. Acta Mater, 2012, 60: 5370-5379

31 Schuster BE, Wei Q, Hufnagel TC, et al. Size-independent strength and deformation mode in compression of a Pd-based metallic glass. Acta Mater, 2008, 56: 5091-5100

32 Chen CQ, Pei YT, De Hosson JTM. Effects of size on the mechanical response of metallic glasses investigated through in situ tem bending and compression experiments. Acta Mater, 2010, 58: 189-200

33 Li FC, Wang S, He QF, et al. The stochastic transition from size dependent to size independent yield strength in metallic glasses. J Mech Phys Solids, 2017, 109: 200-216

34 Maaß R, Löffler JF. Shear-band dynamics in metallic glasses. Adv Funct Mater, 2015, 25: 2353-2368

35 Sun BA, Pauly S, Tan J, et al. Serrated flow and stick-slip deformation dynamics in the presence of shear-band interactions for a $\mathrm{Zr}$-based metallic glass. Acta Mater, 2012, 60: 4160-4171

36 Li P. Effects of strain rates on shear band and serrated flow in a bulk metallic glass. J Non-Crystalline Solids, 2018, 484: 30-35

37 Liu YH, Wang G, Pan MX, et al. Deformation behaviors and mechanism of Ni-Co-Nb-Ta bulk metallic glasses with high strength and plasticity. J Mater Res, 2011, 22: 869-875

38 Zhang ZF, Zhang H, Shen BL, et al. Shear fracture and fragmentation mechanisms of bulk metallic glasses. Philos Mag Lett, 2006, 86: 643-650

Acknowledgements This research was supported by the National Key Research and Development Plan (2018YFA0703603), Guangdong Major Project of Basic and Applied Basic Research, China (2019B030302010), the National Natural Science Foundation of China (51822107, 11790291 and 61888102), and the Strategic Priority Research Program of Chinese Academy of Sciences (XDB30000000).

Author contributions Wang YT and He QF conducted the experiments; Wang YT performed the data analysis and wrote the draft of this manuscript. Wang ZJ and Li MX provided help in the preparation of specimens. Sun BA, Yang Y, Liu YH and Wang WH contributed to the theoretical analyses. All authors contributed to the general discussion. 
Conflict of interest The authors declare no conflict of interest.

Supplementary information Supporting data are available in the online version of the paper.

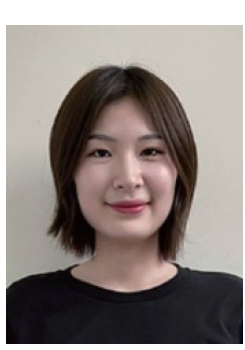

Yu-Tian Wang is a $\mathrm{PhD}$ candidate in materials science at the Institute of Physics, Chinese Academy of Sciences, supervised by Prof. Bao-an Sun. His research focuses on the mechanical behavior of metallic glasses.

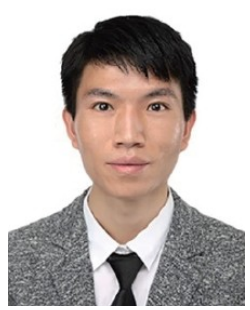

Quan-Feng $\mathrm{He}$ is a postdoctoral fellow at the Department of Mechanical Engineering, the City University of Hong Kong. He received his $\mathrm{PhD}$ degree from the City University of Hong Kong in 2019 under the supervision of Prof. Yong Yang. Then, he conducted his postdoctoral research in Prof. Yong Yang's group. His research interests include the development and characterization of high-preference/high-entropy alloys and metallic glasses.
Ir-Ni-Ta高温非晶合金在微纳尺度下具有极高剪切稳 定性

王雨田 ${ }^{1 \dagger}$, 赫全峰 ${ }^{3 \dagger}$, 王子鉴 ${ }^{1}$, 李明星 ${ }^{1,2}$, 柳延辉 ${ }^{1,2}$, 杨勇 $3^{*}$, 孙保安 ${ }^{1,2 *}$, 汪卫华 ${ }^{1,2}$

摘要 $\mathrm{Ir}-\mathrm{Ni}-\mathrm{Ta}$ 金属玻璃具有一系列优异的高温性能, 使其在高温或恶 劣环境下具有良好的应用前景. 然而, Ir-Ni-Ta块体金属玻璃非常脆, 甚 至在塑性屈服之前就经常发生灾难性断裂, 这大大削弱了其高强度的 优势. 我们的研究表明 Ir-Ni-Ta金属玻璃本质上并不是脆性的, 当样品 尺寸减小到微/纳米尺度时具有良好的延展性. 所有进行测试的 Ir-Ni$\mathrm{Ta}$ 金属玻璃微柱(直径在 $500 \mathrm{~nm}-5 \mu \mathrm{m}$ 之间)均显示出大于 $25 \%$ 的塑性应 变(最大值高达 $35 \%$ ), 同时它们的屈服强度最高可达7 GPa，远远超过迄 今为止所有金属材料的强度记录. $\mathrm{Ir}-\mathrm{Ni}-\mathrm{Ta}$ 金属玻璃的本征剪切稳定性 用剪切带在单个剪切事件中的归一化剪切位移进行表征, 远大于具有 良好延展性的 $\mathrm{Zr} / \mathrm{Cu}$ 基金属玻璃. 因此, $\mathrm{Ir}-\mathrm{Ni}-\mathrm{Ta}$ 金属玻璃可作为在高 温或极端条件下工作的微/纳米器件的候选材料. 